\title{
O uso de linguagem documentária em catálogos coletivos de bibliotecas universitárias: um estudo de avaliação sociocognitiva com protocolo verbal
}

Vera Regina Casari Boccato

Professora Adjunta do Departamento de Ciência da Informação do Centro de Educação e Ciências Humanas da Universidade Federal de São Carlos DCI/CECH-UFSCar.

Mariângela Spotti Lopes Fujita

Professora Titular do Departamento de Ciência da Informação da Faculdade de Filosofia e Ciências da Universidade Estadual Paulista DCI/FFC-UNESP - Campus de Marília.

Avaliou-se o uso de linguagem documentária alfabética de catálogos coletivos, na perspectiva das bibliotecas universitárias e no contexto sociocognitivo dos indexadores e dos usuários. Concluiu-se que o uso adequado de linguagens documentárias de áreas científicas especializadas faz-se por meio da avaliação quanto à atualização, especificidade e compatibilidade para atender às necessidades de indexação e recuperação da informação.

Palavras-chave: Linguagem Documentária; Avaliação; Metodologia qualitativa sociocognitiva; Catálogos públicos de acesso online; Bibliotecas universitárias; Protocolo verbal. 


\title{
The use of indexing language in collective catalogs of university libraries: a study of socio-cognitive evaluation with verbal protocol
}

\begin{abstract}
We have realized an evaluation study of the alphabetic indexing language use of the online collective catalogs in the perspective of the university libraries and in the sociocognitive context of indexers and users. of the university libraries. We have concluded that the adequate use of indexing languages of specialized scientific areas becomes by means of evaluation as to updating, specificity and compatibility in order to meet the needs of indexing and information retrieval.
\end{abstract}

Keywords: Indexing language; Evaluation; Qualitativesocio-cognitive methodology; Public catalogs of online access; University libraries; Verbal Protocol.

Recebido em 06.12.2009 Aceito em 18.10.2010

\section{Introdução}

Inserida no contexto da Organização e Representação do Conhecimento, a nossa pesquisa tem por temática a avaliação do uso de linguagens documentárias alfabéticas de áreas científicas especializadas em catálogos coletivos de bibliotecas universitárias. Para contextualizar o problema de pesquisa, no referido tema, foi necessário o enfoque em três aspectos específicos, a saber: 1) fundamentação teórica e metodológica da área de Organização e Representação do Conhecimento para linguagens documentárias; 2) o catálogo online; e 3) áreas científicas especializadas.

Esses três aspectos retratam a convergência existente entre eles, considerando-se que os catálogos coletivos de bibliotecas universitárias, inseridos em um contexto de áreas científicas especializadas, necessitam de instrumentos de organização e recuperação da informação compatíveis com suas características e da sua comunidade usuária, frente à fundamentação teórica e metodológica da área de Organização e Representação do Conhecimento para linguagens documentárias.

Os bibliotecários indexadores desenvolvem a atividade de tratamento temático da informação por meio da adoção de sistemas de organização do conhecimento, a exemplo das linguagens documentárias 
alfabéticas, vistas como um dos componentes dos catálogos coletivos online. Por sua vez, os usuários de bibliotecas universitárias visualizam essa prática profissional mediante a utilização desse catálogo, como um produto que possibilita a recuperação, a localização e o intercâmbio de variados recursos informacionais.

Nesse contexto, as opiniões e as observações dos bibliotecários e dos usuários são colaborativas para a consolidação desses processos, pois eles devem ser vistos como indivíduos que interagem, compreendem e interpretam o seu meio e, ao mesmo tempo, compartilham os seus conhecimentos adquiridos com uma comunidade de intérpretes. (PINTO, 2005).

Sobre isso, Hjørland (2002) relata que as visões sociocognitivas estão interessadas na cognição individual, porém as abordam a partir do contexto social. Nesse sentido, o processo de conhecimento individual está associado ao contexto histórico, social e cultural das unidades e sistemas de informação responsáveis pela organização e recuperação da informação.

Nessa perspectiva, observamos a inexistência de estudos sobre a avaliação do uso de linguagens documentárias alfabéticas pelo contexto sociocognitivo dos bibliotecários indexadores e usuários, como contribuintes para o aprimoramento dos serviços e produtos oferecidos pelas bibliotecas universitárias, isto é, não existem pesquisas, nesse contexto, que considerem as opiniões por parte dos informantes, integrantes de grupos sociais de áreas científicas especializadas.

Diante do exposto, a proposição da nossa pesquisa é realizar um estudo de avaliação do uso de linguagem documentária alfabética de catálogos coletivos online, com enfoque nas tecnologias de representação e recuperação da informação, na perspectiva das bibliotecas universitárias e no contexto sociocognitivo dos bibliotecários indexadores e dos usuários.

Com essa proposição, a pesquisa tem como objetivo contribuir para - uso adequado de linguagens documentárias alfabéticas, em áreas científicas especializadas nos processos de indexação e recuperação da informação em catálogos coletivos online de bibliotecas universitárias, visando colaborar com o processo de mudanças contínuas nos fazeres bibliotecários e, consequentemente, nos de sua comunidade usuária.

Dessa forma, o nosso estudo foi estruturado em sete seções, apresentando a relação entre o problema e o objetivo da pesquisa e suas seções de forma a explicitar a integração e a coerência entre elas.

\section{As linguagens documentárias alfabéticas nos catálogos coletivos online de bibliotecas universitárias}

Muitos estudos têm sido desenvolvidos na área de Organização e Representação do Conhecimento, com o propósito de apresentar princípios teóricos e metodológicos colaborativos para a formação de concepções epistemológicas que possibilitaram o desenvolvimento de processos e a 
aplicação de procedimentos no âmbito da sistematização e representação do conhecimento.

As fundamentações de Zeng (2008) são colaborativas desse cenário, relatando que os sistemas de organização do conhecimento devem ser estruturados em um plano multidimensional, transpondo fronteiras culturais e geográficas de acesso e representação, sem desconsiderar suas funções principais que incluem a eliminação da ambiguidade, o controle de sinônimos e o estabelecimento de relacionamentos semânticos. Eles são representados por esquemas de classificação, listas de cabeçalhos de assunto, taxonomias, tesauros, ontologias, entre outros.

As exposições de Zeng (2008), complementadas pela norma ANSI/NISO Z39.19 (2005), Lancaster (1987; 2004) e Beghtol (2002) apontam para as linguagens documentárias alfabéticas serem construídas a partir das linguagens de especialidades e de busca do usuário, de diretrizes internacionais estabelecidas e de acordo com os princípios de garantia literária e garantia de uso, bem como da garantia cultural, vistas como instrumentos de apoio importantes para a indexação e recuperação da informação em sistemas de recuperação da informação de bases de dados eletrônicas, catálogos coletivos informatizados, bancos de dados, repositórios e gerenciadores de publicações eletrônicas.

As linguagens documentárias devem ser construídas com base na terminologia de uma área, com categorias e subcategorias delimitadas, a partir de relações lógico-semânticas de termos claros e bem definidos, possibilitando uma representação adequada para a recuperação da informação. Para tanto, a Terminologia, também, possui fundamental importância nesse processo, fornecendo diretrizes para a compilação de termos e o estabelecimento de relações conceituais entre si.

As linguagens documentárias visam à organização e à disseminação de conteúdos informacionais de sistemas de informação, tais como as bibliotecas universitárias, que exigem melhor controle da terminologia para um desempenho adequado da recuperação e filtragem de informações.

Gil Urdiciain (2004) expõe que a linguagem documentária atua em duas fases do processo documentário: nos momentos da descrição e da recuperação da informação. Ela apresenta-se como uma linguagem de intermediação, servindo de "ponte" entre as informações contidas nos documentos e as informações solicitadas pelo usuário. Assim, podemos considerar que sua função é a de mediar as linguagens empregadas pelo autor do documento e pelo próprio usuário do sistema. Quem realiza esse processo de estabelecer "pontes" entre a solicitação do usuário e as informações contidas nos documentos é o bibliotecário, um dos profissionais atuantes na área de Organização do Conhecimento, principalmente no processo da recuperação da informação.

Dessa maneira, as linguagens documentárias têm um papel fundamental nos processos de indexação e recuperação da informação, pois como componente dos catálogos coletivos online, atuam nos dois 
momentos do tratamento da informação, isto é, na entrada e na saída de dados nesses sistemas de recuperação da informação.

Fernández Molina e Moya Anegón (1998) consideram que os catálogos online são sistemas automatizados de recuperação da informação que se encontram disponíveis de maneira mais geral e os primeiros a que recorre qualquer usuário, quando tem uma necessidade de informação.

Os fundamentos teóricos da área de Organização e Representação do Conhecimento destacam a importância da década de 1960 na prática da catalogação descritiva com a introdução do $A A C R$, 1st edition em 1967, publicado pela American Library Association $(A L A)^{1}$, baseado na Declaração de Princípios de Catalogação apresentado na Conferência Internacional sobre Princípios de Catalogação, realizada na França em 1961 (SHANNON; GIBBS, 1996).

Quarenta anos mais tarde, em 2003, ocorreu em Frankfurt o $1^{\circ}$. Encontro de Especialistas sobre um Código de Catalogação Internacional, também conhecido como "Princípios de Frankfurt". Nessa Conferência, as funções do catálogo foram articuladas e, correspondendo ao ambiente de catálogos online, os Princípios de Paris foram expandidos para o domínio da descrição bibliográfica de assunto, bem como sobre os modelos conceituais estabelecidos pela International Federation of Library Associations (IFLA, 2003).

A evolução da representação e recuperação da informação, viabilizada pelos avanços tecnológicos, pode ser presenciada também com a agilização da atividade de descrição, por meio da catalogação cooperativa, que permite a importação de registros padronizados existentes em outros sistemas de recuperação da informação de diversas bibliotecas, de acordo com normas internacionais, com a finalidade de intercambiá-los, contribuindo na formação de Bancos de Dados Bibliográficos online (CRUESP/BIBLIOTECAS, 2006).

Esse processo propicia vantagens em termos de tempo, pois a catalogação de uma obra será muito mais rápida e fácil e, consequentemente, com um custo menor. A catalogação cooperativa deve ser realizada cuidadosamente e, especificamente, no âmbito do tratamento temático da informação, observados os princípios norteadores para a realização de uma indexação com qualidade, resultante do desenvolvimento da indexação durante a catalogação, de acordo com uma política de indexação definida e adotada pelo sistema e com o uso apropriado das linguagens documentárias alfabéticas como sistemas de organização do conhecimento.

Pode-se concluir que o uso adequado da linguagem documentária faz-se necessário para garantir a realização, com qualidade, dos processos de indexação e de recuperação da informação, praticadas pelos bibliotecários indexadores e pelos usuários. As mudanças de paradigmas no âmbito da indexação, como processo de representação da informação

\footnotetext{
${ }^{1}$ ANGLO American Cataloguing Rules. Prepared by American Library Association. Division of Cataloging Classification. Chicago: ALA, 1967. 400 p.
} 
na construção de catálogos online, a partir da proposta de utilização dos $F R B R s^{2}$, são colaborativas nesses processos, bem como para a construção e modelagem de catálogos online centrados no usuário e no contexto social que envolve o processamento da informação, realizada por equipes multidisciplinares e integradas - bibliotecários, usuários, autores, designers de catálogos, analistas de sistemas, entre outros - valorizadas pela presença dos bibliotecários como contribuintes no delineamento de pontos de acesso, exemplificados, também, pelos acessos analíticos de assunto, autor e título e por outros recursos aplicáveis à representação e recuperação da informação. Nessa perspectiva, torna-se fundamental o uso adequado de uma linguagem documentária que retrate não só o perfil do catálogo, mas também de sua comunidade usuária e, nesse sentido, os estudos de avaliação de linguagens documentárias subsidiam na escolha do sistema de organização do conhecimento mais apropriado no atendimento de tais finalidades.

\section{Estudos de avaliação de linguagens documentárias nos sistemas de recuperação da informação: as abordagens metodológicas}

Quando abordamos os "estudos e os métodos de avaliação de linguagens documentárias nos sistemas de recuperação da informação", verificamos a correspondência existente entre essas temáticas e a epistemologia da Ciência da Informação, que envolve pontos de vista independentes, contribuintes na consolidação desse campo científico. Várias vertentes influenciaram o desenvolvimento da área, delimitando paradigmas $^{3}$ epistemológicos distintos, embora inter-relacionados e complementares, caracterizados pela existência de visões fisicistas (paradigma físico - centrado no sistema), cognitivas (paradigma cognitivo - centrado no usuário) e sociocognitivas (paradigma social - interação do usuário individual e do ambiente social/organizacional), no processo de recuperação da informação (OLSON; BOLL, 2001; CAPURRO, 2003).

O paradigma físico valoriza o sistema de recuperação da informação e o processo de transmissão de mensagens e, inserido nesse contexto, consideramos o catálogo coletivo online como o "físico", o registro bibliográfico como o emissor, que transmite a informação para o usuário (receptor), que recebe a mensagem. Essa informação será codificada para ser transmitida como mensagem pela linguagem documentária (canal de comunicação) que, em seguida, é decodificada pelo usuário (receptor),

\footnotetext{
${ }^{2}$ Functional Requirements of Bibliographic Records (FRBR), Functional Requirements of Authority Data (FRAD) (em fase de revisão) e Functional Requirements for Subject Authority Records (FRSAR) (em desenvolvimento)

${ }^{3}$ Paradigma é um conjunto de realizações científicas reconhecidas por uma determinada comunidade que, durante algum tempo, fornecem problemas e soluções modelares que podem ser identificados no seu campo de atuação (KUHN, T. S. Estrutura das revoluções científicas. 7. ed. São Paulo: Perspectiva, 2003. 257 p.).
} 
compartilhando o mesmo código do registro bibliográfico (emissor). 0 esquema de comunicação possibilita a retroalimentação do processo (feedback), podendo ocasionar o ruído (indexação não pertinente ao documento recuperado) ou o silêncio (indexação indevida e, assim, o documento não é recuperado), no processo de recuperação da informação registrada em suportes documentários.

Em contraposição à presença dos estudos de avaliação com abordagem quantitativa, a partir da década de 1970, verificamos uma mudança da visão fisicista para a cognitiva, sinalizando o desenvolvimento dos estudos de avaliação centrados no usuário.

No paradigma cognitivo, o usuário se coloca em uma posição ativa que elabora ideias, conceitos, etc., em um contexto individual. Esse cenário é visto pela ótica da dimensão humana, isto é, pela perspectiva centrada no usuário, pois os sistemas de recuperação da informação devem ser modelados de acordo com o usuário, com a natureza de suas necessidades de informação e com seus padrões de comportamento na busca e no uso da informação.

Todavia, a partir da década de 1990, as abordagens cognitivas têm sido analisadas e criticadas por diversos pesquisadores que, além de relevarem os processos cognitivos dos indivíduos para a realização de processos documentários e no delineamento de construção de sistemas de recuperação da informação, agregam o "contexto" como um elemento importante, ressaltando uma visão sociocognitiva, na efetivação desse processo.

Segundo Almeida et. al (2007, p. 22):

O Paradigma Social enfoca a recuperação dos elementos subjetivos dos usuários para a definição do desenho dos sistemas de recuperação, considerando sua visão de mundo. A partir dessa concepção, a Ciência da Informação volta-se para um enfoque interpretativo, centrado no significado e no contexto social do usuário e do próprio sistema de recuperação da informação.

A visão dos autores (ALMEIDA et al., 2007, p. 22), subsidiada por Capurro (2003) conduz-nos ao entendimento de que a construção de um sistema de recuperação da informação tem como ponto focal o usuário e suas necessidades de informação. Este, por sua vez, desempenhando papel ativo em um contexto sócio-cultural, permite o armazenamento e realiza a recuperação e a interpretação dos registros bibliográficos disponibilizados. Assim, o indivíduo é visto como integrante de uma sociedade e, dessa forma, os estudos desenvolvidos a partir dessa abordagem consideram os fenômenos inseridos em um contexto social.

No desenvolvimento de pesquisas na área de Ciência da Informação - com destaque para a temática avaliação de linguagens documentárias, verificamos que as teorias sobre os métodos quantitativo e qualitativo inserem-se nesse importante cenário teórico-científico, retratado pelos paradigmas físico e cognitivo, demonstrando a aplicabilidade dessas 
abordagens em estudos de avaliação centrados no sistema e no usuário, não sendo contemplados estudos de avaliação de linguagens documentárias pela abordagem sociocognitiva a partir das concepções epistemológicas advindas do paradigma social.

A metodologia quantitativa ${ }^{4}$, representativa do paradigma físico, possibilita a realização de levantamento de informações junto a um maior número de respondentes, as análises estatísticas e, usualmente, a comparação e a generalização de resultados.

Nessa perspectiva, ressaltamos os estudos clássicos de avaliação de linguagens documentárias Projetos Cranfield I e Cranfield II desenvolvidos, respectivamente, em 1957 e 1963 (FOSKETT, 1973), a pesquisa de Lancaster (1968), com o estabelecimento dos parâmetros e índices quantitativos de previsão e revocação aplicáveis na avaliação de sistemas de recuperação da informação exemplificados pelo Sistema MEDLARS e o Teste de Aberystwyth, desenvolvido em 1970, arrolando a questão da especificidade como quesito de suma importância na concepção de linguagens documentárias alfabéticas, além das pesquisas de Torres (1992) e de Oliveira, Alves e Vicente (1997), que tiveram como objeto de estudo empírico a Lista de Cabeçalhos de Assunto da Rede BIBLIODATA (LCARB), interesse particular de nosso estudo.

Sobre a metodologia qualitativa ${ }^{5}$, esta trabalha com o universo de interpretações, significados, crenças, valores e atitudes, apresentando estreitas relações com os fundamentos teórico-conceituais advindos do paradigma cognitivo da área de Ciência da Informação, demonstrando a mudança da visão fisicista para a cognitiva, caracterizando a elaboração dos estudos de avaliação orientados pelo usuário.

As pesquisas qualitativas de avaliação de linguagens documentárias desenvolvidas por Owens e Cochrane (2004) e por Toews (2007) são exemplos desse cenário metodológico, retratando a importância da utilização de diretrizes e normas internacionais na construção de sistemas de organização do conhecimento compatíveis com a necessidade de busca dos usuários. A metodologia qualitativa propicia o envolvimento direto com pessoas, lugares e processos interativos, originando uma coleta descritiva pautada no rigor que deve existir no momento da análise interpretativa dos dados.

Salientamos que no contexto da metodologia qualitativa, a abordagem cognitiva faz-se presente na área de Ciência da Informação na realização de pesquisas sobre o tratamento temático e a recuperação da informação, demonstrando as ações praticadas pelos bibliotecários e usuários no desenvolvimento desses processos.

Assim, as pesquisas que utilizam a metodologia qualitativa-cognitiva evidenciam a subjetividade da atividade mental presente na atuação profissional dos bibliotecários e dos usuários, demonstrada a partir de

\footnotetext{
${ }^{4}$ Também denominada de abordagem quantitativa, abordagem quantitativa realista e pesquisa quantitativa.

${ }^{5}$ Também denominada de abordagem qualitativa e pesquisa qualitativa.
} 
ações que proponham revelar aspectos implícitos nas estruturas de conhecimento desses profissionais e usuários (DAL'EVEDORE; FUJITA, 2008).

Os trabalhos da Profa. Dra. Brenda Dervin (1983; 2003) sobre a abordagem sense-making, inicialmente aplicada na área de Ciências da Comunicação, contribuíram com o desenvolvimento das abordagens cognitivas.

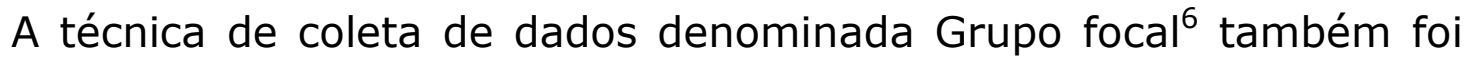
empregada nas pesquisas qualitativas-cognitivas, inicialmente na área de Marketing e, em seguida, nas Ciências Sociais, Ergonomia, Ciências da Saúde, Ciência da Informação, entre outras.

No campo da Ciência da Informação, a pesquisa de Connaway, Johnson e Searing (1997) foi desenvolvida na University of Winsconsin Madison Campus, aplicando a técnica do grupo focal para analisar o desempenho do catálogo online da biblioteca, denominado UW-Madison's Online System - com destaque para a avaliação da linguagem documentária adotada pelo catálogo da University of Winsconsin-Madison, pela perspectiva dos usuários.

A técnica introspectiva do Protocolo Verbal ou "Pensar Alto" (Think Aloud) é aplicada a estudos de avaliação qualitativa, onde os sujeitos, em voz alta, expressam o que pensam e o que ocorre em suas mentes durante a execução de uma tarefa. Essas declarações são gravadas, observando-se também o comportamento dos sujeitos, como expressões faciais (gestos e movimentos dos olhos). Dessa maneira, a linguagem do pensamento realiza muitos processos cognitivos como a percepção e o raciocínio.

No Brasil, entre vários estudos desenvolvidos com o emprego dessa técnica, a dissertação de mestrado de Nardi (1993) abriu a possibilidade de uso de um instrumento de coleta de dados e, também, para a observação da leitura documentária dentro do Grupo de Pesquisa "Análise Documentária" da UNESP - Campus de Marília". As pesquisas no Brasil, desenvolvidas por Fujita, Nardi e Fagundes (2003) e por Fujita (2003), na observação da leitura documentária, apresentam excelentes resultados no uso do Protocolo Verbal, demonstrando novos aspectos da leitura documentária entre outras contribuições.

Com a utilização da técnica do Protocolo Verbal, os usuários "pensam em voz alta", emitindo suas opiniões e comentários acerca do objeto avaliado, realizando uma avaliação cooperativa e participativa: usuários participam da identificação e entendimento de problemas de recuperação da informação e utilização do sistema, em seu próprio ambiente de trabalho.

Esse ponto de vista é reafirmado por Fujita, Nardi e Fagundes (2003, p. 142), expondo que Ingwersen (1982, p. 173-174) deu atenção

\footnotetext{
${ }^{6}$ Também nomeada por grupo de foco ou entrevistas de grupo focal.
} 
especial à utilização dessa técnica, que garantiu a realização de ações íntegras e válidas:

[...] a coleta de dados dos sujeitos em situação natural, em seu próprio ambiente de pesquisa e sem inserir qualquer mudança em suas rotinas; complementação dos dados de "Pensar Alto" com observação do comportamento e ações dos sujeitos; treinamento do sujeito (familiarização com a técnica).

Diante do exposto e por considerar de fundamental importância a observação do usuário para a avaliação de linguagem documentária, Boccato (2005) desenvolveu um trabalho de pesquisa com a proposta de avaliar, pela perspectiva do usuário, a linguagem documentária Descritores em Ciências da Saúde (DeCS), utilizada para a recuperação da informação no sistema Literatura Latino-americana em Ciências da Saúde (LILACS), produzido pela BIREME, com o intuito de obter indicadores para delinear as estratégias de aprimoramento da linguagem na área de Fonoaudiologia. O estudo levou a uma reflexão sobre as declarações emitidas pelos quatro sujeitos participantes dessa pesquisa e os resultados obtidos da análise revelaram que a linguagem DeCS, em Fonoaudiologia, conduziu as buscas a resultados insatisfatórios, quanto à recuperação da informação a partir dos seguintes aspectos relevantes: insuficiência de termos genéricos e específicos representativos da área de Fonoaudiologia; necessidade de atualização de termos disponíveis na linguagem com relação à terminologia encontrada na literatura científica da área e adotada pelos especialistas; e hierarquização de termos em categorias de assuntos não equivalentes aos seus conceitos, entre outros aspectos.

Em síntese, no desenvolvimento de pesquisas na área de Ciência da Informação - com destaque para a temática avaliação de linguagens documentárias, verificamos que os métodos quantitativo e qualitativo inserem-se nesse importante cenário teórico-científico, retratado pelos paradigmas físico e cognitivo, demonstrando a aplicabilidade dessas abordagens em estudos de avaliação centrados no sistema e no usuário, não sendo contemplados estudos de avaliação de linguagens documentárias pela abordagem sociocognitiva a partir das concepções epistemológicas advindas do paradigma social, que considera o usuário inserido em seu meio social.

\section{0 contexto sociocognitivo do bibliotecário indexador e do usuário em bibliotecas universitárias}

O contexto sociocognitivo visa à representação e à recuperação da informação, por meio da visão do indivíduo inserido no seu contexto sóciocultural-histórico, partindo do pressuposto de que a necessidade de 
informação do usuário é construída de fora para dentro, isto é, o seu meio influenciando e contribuindo para a construção dessa necessidade, que será representada por seus modelos mentais, associado à sua concepção de mundo, refletindo no seu interesse real de informação.

O contexto realiza a intermediação entre a situação real dentro da biblioteca - norteada pelas concepções de análise de assunto utilizadas pelo bibliotecário indexador, e o sistema linguístico - linguagem documentária adotada pelo sistema, caracterizado pela representação dos documentos indexados.

De acordo com Gonçalves (2008, p. 28-29), o contexto sociocognitivo do bibliotecário indexador refere-se ao...

[...] conhecimento prévio que o profissional tem sobre a sua ferramenta de trabalho (a política de indexação, as regras e os procedimentos do manual de indexação, a linguagem documentária) e as reais necessidades dos usuários. Por conseguinte, ele deve conhecer o contexto físico, ao qual a instituição e/ou o sistema de informação estão vinculados através da missão, objetivos, planejamentos estratégicos e filosofia (grifo nosso).

A prática da indexação conduz à adoção, pelo bibliotecário indexador, de uma concepção de assunto em que deve estar intimamente relacionada aos objetivos institucionais estabelecidos e do próprio sistema de recuperação da informação, explicitados pela política de indexação. Essas concepções de análise, que acreditamos afetar o desempenho do bibliotecário indexador, são classificadas em: concepção simplista, concepção orientada pelo conteúdo e concepção orientada para a demanda (ALBRECHTSEN, 1993, p. 220-222).

Quanto ao usuário, Gonçalves (2008) caracteriza o seu conhecimento prévio pela universidade, pelos grupos de pesquisas e pelo catálogo coletivo online, elementos esses que o norteiam e influenciam na manifestação de sua necessidade de informação, concomitante com os seus processos cognitivos na concretização dessa necessidade.

Dessa forma, o contexto sociocognitivo é um elemento a ser considerado no desenvolvimento do processo de indexação a partir da leitura documentária, visando à análise e à representação da informação, condizentes com as necessidades de busca do usuário. Associados ao aspecto sociocognitivo, os aspectos físico e psicológico são fundamentais na formação do contexto do bibliotecário indexador, como variável de suma importância na construção desse processo. A linguagem documentária, vista como o conhecimento prévio profissional e especializado do bibliotecário indexador, deve possibilitar a correspondência mais fiel possível dos conteúdos dos documentos e das necessidades informacionais dos usuários, expressas por seu repertório advindo do seu conhecimento prévio constituído pela universidade, pelos 
grupos de pesquisas, pela grade curricular das disciplinas científicoacadêmicas e pelo próprio sistema de recuperação da informação.

Nessa vertente, as visões holística e coletiva dos bibliotecários indexadores e dos usuários são privilegiadas, contribuintes para a definição de um tratamento temático da informação e na modelagem e na construção de sistemas de recuperação da informação. A partir dessa concepção, a área de Ciência da Informação volta-se para uma dimensão teórica focada por abordagens interpretativas, centradas no aspecto semântico e no contexto social da informação, do bibliotecário indexador e do usuário.

Nesse sentido, a nossa pesquisa contextualiza-se entre o deslocamento do paradigma cognitivo para o paradigma social, que coloca o contexto do bibliotecário indexador e do usuário no centro dos processos informacionais, caracterizados pela representação e recuperação da informação e do conhecimento. Portanto, esta pesquisa está centrada no contexto sociocognitivo dos bibliotecários indexadores e dos usuários nas perspectivas teóricas de Hjørland (1997, p. 118), que preconiza a adoção de uma "abordagem metodológica coletivística", quanto à proposta de se realizar um estudo de avaliação do uso de linguagem documentária de catálogos coletivos online de áreas científicas especializadas de bibliotecas universitárias, com enfoque nas tecnologias de representação e recuperação da informação, utilizando o protocolo verbal como técnica de coleta de dados.

A técnica do protocolo verbal, vista pela abordagem sociocognitiva, tem como enfoque o sujeito no momento da realização de uma determinada atividade e sua cognição em relação ao seu contexto de produção. Referente ao bibliotecário indexador, o interesse é o tratamento temático da informação, especificamente a indexação e o uso que fará da linguagem documentária durante a representação da informação. Pela perspectiva do usuário, o enfoque é a recuperação da informação por assunto, por meio do uso da linguagem na busca de suas necessidades informacionais, interagindo com seu meio ambiente.

\section{Metodologia}

As coletas de dados foram realizadas em uma amostra de nove bibliotecas da Universidade Estadual Paulista (UNESP), das três áreas do conhecimento: Ciências Exatas, Ciências Humanas e Ciências Biológicas, respectivamente, dos cursos de Engenharia Civil, Pedagogia e Odontologia, tendo como objeto de estudo empírico a Lista de Cabeçalhos de Assunto da Rede BIBLIODATA, utilizada nos processos de indexação e recuperação da informação no catálogo coletivo online ATHENA, conforme demonstrado pelo QUADRO 1, a seguir: 


\section{QUADRO 1}

Seleção das bibliotecas universitárias da UNESP e respectivas identificações

\begin{tabular}{|c|c|c|c|}
\hline CURSOS & ÁREAS & BIBLIOTECAS & IDENTIFICAÇÃO \\
\hline \multirow{3}{*}{ Engenharia Civil } & \multirow[t]{3}{*}{ Ciências Exatas } & 1. Bauru & E1 \\
\hline & & 2. Guaratinguetá & E2 \\
\hline & & 3. Ilha Solteira & E3 \\
\hline \multirow{3}{*}{ Pedagogia } & \multirow[t]{3}{*}{ Ciências Humanas } & $\begin{array}{l}\text { 4. Presidente } \\
\text { Prudente }\end{array}$ & H1 \\
\hline & & 5. Rio Claro & H2 \\
\hline & & $\begin{array}{l}\text { 6. São José do Rio } \\
\text { Preto }\end{array}$ & H3 \\
\hline \multirow{3}{*}{ Odontologia } & \multirow{3}{*}{$\begin{array}{l}\text { Ciências } \\
\text { Biológicas }\end{array}$} & 7. Araçatuba & B1 \\
\hline & & 8. Araraquara & B2 \\
\hline & & $\begin{array}{l}\text { 9. São José dos } \\
\text { Campos }\end{array}$ & B3 \\
\hline
\end{tabular}

Fonte: BOCCATO, 2009, p. 137.

A metodologia constituiu-se de estudo diagnóstico composto por três partes: 1) estudo do funcionamento e procedimentos no tratamento de informações documentárias na Rede de Bibliotecas da UNESP, na perspectiva da Coordenadoria Geral de Bibliotecas (CGB); 2) estudo do funcionamento e procedimentos no tratamento de informações na Rede de Bibliotecas da UNESP, na perspectiva do catalogador ${ }^{7}$; e 3) avaliação do acesso e recuperação da informação online pelo usuário.

Para a realização da primeira parte foram aplicados questionários de diagnóstico organizacional aos diretores das bibliotecas universitárias. A elaboração do questionário foi fundamentada no diagnóstico organizacional exposto por Almeida (2005, p. 53-55).

$\mathrm{Na}$ segunda parte, sobre o funcionamento e procedimentos no tratamento de informações na Rede de Bibliotecas da UNESP, na perspectiva do catalogador, utilizamos a abordagem cognitiva com a técnica introspectiva do Protocolo Verbal, nas seguintes modalidades:

a) Protocolo verbal individual realizado com bibliotecários catalogadores para identificação dos procedimentos de análise de assunto e representação na catalogação de livros, bem como dificuldades e restrições; e

b) Protocolo Verbal em Grupo com bibliotecários chefes das bibliotecas, bibliotecários catalogadores, bibliotecários de referência, usuários docentes pesquisadores, líderes ou membros de grupos de pesquisa e usuários discentes de graduação, para acesso ao conhecimento dos sujeitos que participam do contexto de tratamento de conteúdos

\footnotetext{
${ }^{7}$ No contexto da Rede de Bibliotecas da UNESP, os bibliotecários indexadores correspondem aos bibliotecários catalogadores que desenvolvem as atividades de catalogação e indexação.
} 
documentários de bibliotecas universitárias, como fonte de coleta de dados qualificada do diagnóstico.

Na terceira parte, relativa à avaliação do acesso e recuperação da informação online pelo usuário, foram realizados protocolos verbais individuais com usuários discentes de graduação de primeiro e últimos anos $^{8}$, dos cursos citados anteriormente.

Dessa forma, os procedimentos adotados para as aplicações do diagnóstico organizacional nas bibliotecas universitárias e dos protocolos verbais em grupos $\mathrm{e}$ individuais, foram realizados com 0 intuito de caracterizar o contexto organizacional/acadêmico da Rede de Bibliotecas da UNESP e de observar as visões dos bibliotecários catalogadores e dos usuários para a análise das ações e opiniões dos sujeitos participantes no contexto, respectivamente, da indexação durante a catalogação e da recuperação da informação.

Foram realizadas trinta e seis coletas de dados referentes a nove protocolos verbais em grupo, nove protocolos verbais individuais com os bibliotecários catalogadores e dezoito protocolos verbais individuais com os usuários discentes. O número total de sujeitos participantes da pesquisa foi de setenta e duas pessoas, sendo quarenta e cinco no protocolo verbal em grupo (entre bibliotecários chefes, bibliotecários catalogadores, bibliotecários de referência, docentes e discentes); e nove bibliotecários catalogadores e dezoito discentes. As coletas foram iniciadas em maio de 2006 e concluídas em setembro de 2007, tendo sido efetuadas no próprio ambiente de trabalho ou de estudo dos sujeitos, isto é, nas dependências das nove bibliotecas da Rede UNESP participantes de nossa pesquisa, previamente agendadas.

As transcrições das coletas geraram uma grande massa de dados. Considerando-se a abordagem sociocognitiva na interação do ambiente organizacional (biblioteca) e das diferentes perspectivas advindas dos diferentes sujeitos participantes das coletas (bibliotecários chefes, bibliotecários de referência, bibliotecários catalogadores e usuários docentes e discentes), observou-se a complexidade que envolveria a análise dessas transcrições e, dessa forma, realizou-se a leitura dos protocolos verbais na íntegra, uma vez que nem sempre a linguagem utilizada pelos sujeitos é a mesma utilizada pela literatura.

Quanto aos procedimentos de análise dos dados coletados e no atendimento dos propósitos de nossa pesquisa, foram elaboradas doze categorias, tendo como base os referenciais teóricos apresentados, os objetivos da pesquisa e as declarações realizadas pelos sujeitos participantes, que contribuíram para a exemplificação de cada fenômeno, de cada categoria, sistematizadas em três eixos temáticos, a saber:

\footnotetext{
8 Nos cursos de Pedagogia e Odontologia, a aplicação do protocolo verbal individual com os usuários dos últimos anos corresponderam aos alunos dos $4^{\circ}$ anos; no curso de Engenharia Civil, os alunos dos últimos anos são os de $5^{\circ}$ anos.
} 
a) Linguagem documentária vista pelo conteúdo: 1) Procedimentos relacionados à indexação; 2) Procedimentos relacionados à representação para indexação; 3) Escolha da linguagem; 4) Escolha do termo; e 5) Desempenho da linguagem no processo de representação para indexação;

b) Linguagem documentária vista pelo uso: Conhecimento/Importância da linguagem; 7) Estratégia de busca; 8) Desempenho da linguagem no processo de recuperação da informação; 9) Capacidade de revocação e precisão do sistema; e 10) Avaliação do sistema de recuperação da informação;

c) Linguagem documentária vista pela forma: 11) Procedimentos de construção, atualização e manutenção da linguagem; e 12) O papel do bibliotecário na construção, atualização e manutenção da linguagem.

\section{Resultados e discussão}

A linguagem documentária foi uma temática muito abordada pelos bibliotecários catalogadores e pelos usuários - docentes e discentes - nos protocolos verbais em grupo e individuais das três áreas do conhecimento, tendo suscitado muitos questionamentos e preocupações sobre o desempenho e a importância desse instrumento de mediação e comunicação entre a indexação e a recuperação da informação nos catálogos coletivos online de áreas científicas especializadas de bibliotecas universitárias.

O contexto sociocognitivo do bibliotecário catalogador da Rede de Bibliotecas da UNESP formado pela universidade, biblioteca, pelo Padrão de Qualidade de Registros Bibliográficos da UNESP, Lista de Cabeçalhos de assunto da Rede BIBLIODATA, linguagens documentárias paralelas, catálogo ATHENA e pelos docentes e discentes de graduação das áreas científicas especializadas influenciou a realização da indexação que nos proporcionou importantes resultados sobre o uso da LCARB, para a representação dos conteúdos documentários no catálogo coletivo online ATHENA. Tais resultados alcançados, a partir das declarações emitidas pelos sujeitos participantes nos Protocolos Verbais em Grupo (PVG) e Individuais (PVI) podem ser verificados, na íntegra, por meio dos Apêndices 1-3, identificados pelas seguintes categorias: Bibliotecário chefe (BR-Ch), Bibliotecário Catalogador participante do Protocolo Verbal em Grupo (BC), Bibliotecário Catalogador participante do Protocolo Verbal Individual (BCI), Bibliotecário de Referência (BR), Docente e Discente.

Dessa maneira, numa análise interpretativo-sintética, o uso da LCARB mostrou-se um instrumento "obrigatório" da Rede UNESP, sendo empregada para a confirmação e validação dos cabeçalhos de assunto a serem descritos no campo 650. Essa constatação, de fundamental importância, está associada a alguns aspectos também explícitos pelos resultados obtidos.

Como primeiro aspecto, verificamos que pelo fato da LCARB não possuir vocabulário especializado e atualizado e por não oferecer uma 
estrutura sintático-semântica consistente, a utilização de sistemas de organização do conhecimento paralelos tornou-se uma prática frequente na busca pela especificidade que o tratamento temático da informação de áreas científicas especializadas exige, por meio da descrição de assuntos no campo 690, refletindo o universo de conhecimentos em que a biblioteca universitária está inserida. Exemplos:

PVI-C - B2 [LCARB não representa satisfatoriamente os assuntos dos documentos]

$((\mathrm{O} / \mathrm{P}))[\ldots]$ Então quanto a catalogação de assunto quando você não tem o assunto no livro, você não encontra no BIBLIODATA você coloca no campo 690 que tem o assunto local. É isso? ((S))Isso. [...] quando não atende a gente vai, agente utiliza outros recursos no caso a gente procura no DeCS da BIREME e a gente coloca no nosso campo 690.

PVG - H3 [inconsistências nas relações sintático-semânticas da LCARB]

\section{Bibliotecário Catalogador}

Eu vou pôr no 650 (campo controlado de assunto da planilha MARC 21 do software ALEPH) "Crianças não sei o que", aí depois a pessoa procura por "Criança" que ela não sabe se está no plural, como é. Ela não sabe, então o quê que eu teria que fazer? Eu teria que fazer um outro 650 e por criança no singular?

A padronização desses assuntos foi uma preocupação manifestada pelos bibliotecários das três áreas do conhecimento, demonstrando a necessidade de adoção de um único instrumento de controle terminológico para a Rede de Bibliotecas, para a descrição de assuntos locais, visando à uniformização dos pontos de acesso de assunto no catálogo coletivo online ATHENA. Sobre isso, a área de Odontologia apresentou-se, também, favorável a essa medida, mesmo possuindo e utilizando um vocabulário controlado, especializado na descrição dos conteúdos documentários para a indexação, no momento em que a LCARB não cumpre tal função.

Esse aspecto resultou nas constatações dos bibliotecários sobre a necessidade do aprimoramento da LCARB e da construção de um vocabulário controlado específico da Rede UNESP e, ainda, a importância da participação do usuário nesse processo.

Entendemos, portanto, que os usuários inseridos em um contexto de áreas científicas especializadas de bibliotecas universitárias requerem documentos representados tematicamente em uma extensão maior de especificidade e com a utilização de termos capazes de "[...] representar o assunto do documento no mesmo nível de extensão em que ele é tratado pelo autor do documento" (TORRES, 1992, p. 45). Essa atitude refletir-se- 
á, imediatamente, no processo de recuperação da informação e nos resultados mais precisos produzidos por buscas por assunto, representativas do conteúdo documentário.

De acordo com as pesquisas de Torres (1992) e Oliveira, Alves e Vicente (1997), observamos que a linguagem documentária deverá oferecer condições para que essa necessidade possa ser atendida, sendo possuidora de um vocabulário especializado que satisfaça a representação de assuntos de áreas científicas, de uma cadeia sintático-semântica expressiva, com relações hierárquicas, de equivalência e não-hierárquicas e que propicie sua compatibilidade com a linguagem de recuperação utilizada pelo usuário.

Quanto ao segundo aspecto sobre o "fazer" bibliotecário, no contexto da indexação, não assistimos a realização de uma adequada indexação como a atividade que contempla as etapas de identificação e seleção de conceitos, com vistas à representação, por meio de uma linguagem documentária alfabética.

Notamos a falta de sistematização na realização da leitura documentária e a existência da prática de levantamento de assuntos, principalmente retirados de fichas catalográficas resultantes da catalogação na publicação, em detrimento da elaboração de uma análise de assunto focada efetivamente no conteúdo do documento. Esse cenário, por sua vez, conduz a uma representação de assuntos não correspondentes ao nível de abordagem em que são tratados pelos autores, havendo uma tendência pela opção do cabeçalho genérico para a representação do conteúdo documentário. Exemplos:

PVI-C - E2 [Catalogação Original] [ficha catalográfica e partes do documento como fonte para a análise de assuntos]

[...] Agora eu vou para o campo do assunto. [...] Eu vou procurar o termo. A gente dá uma olhada na ficha, no título e sempre eu dou uma olhada no sumário, se tem resumo, alguma coisa a gente sempre olha, dá uma lidinha aqui no prefácio, dá uma olhada aqui nos tópicos, as bibliografias, para a gente fazer o levantamento do assunto [...].

PVG - H1 [preocupação com os procedimentos adotados para leitura dos documentos; preocupação do docente sobre como é feita a leitura documentária; ficha catalográfica considerada como fonte para determinação dos assuntos]

\section{Docente}

E outra coisa também que estou pensando, claro que o papel do bibliotecário, ele é treinado para ter olhos e a percepção dos temas e assuntos que os livros tratam, não é? Eu também não sei como é exatamente como é que se define isso na hora 
de catalogar, quer dizer, o que você lê? O que você faz? Você lê a capa...

\section{Docente}

Como você extrai essas informações? Porque se houver uma falha aí nesse momento... [...].

\section{Docente}

É, que não é da área de domínio, como é que você vai fazer? $[\ldots]$.

\section{Bibliotecário Chefe}

Pela ficha catalográfica.

A literatura mostra-nos a concepção da indexação como processo de análise documentária para fins de recuperação da informação formada pelas seguintes etapas básicas: a) análise: leitura e segmentação do texto para a identificação e seleção de conceitos; b) síntese: construção do texto documentário com os conceitos selecionados - diz respeito especialmente à elaboração de resumos; e c) representação: por meio de linguagens documentárias (LANCASTER, 2004).

Fujita (2003) afirma que os processos de análise e síntese sugerem que os textos passam por uma espécie de desestruturação para a construção de outro texto, o documentário. Desse modo, para análise, o texto é segmentado, os conceitos são identificados e selecionados; e para a síntese é feito um processo de condensação do texto e a elaboração de um texto documentário que é um resumo.

Sobre a análise de assunto, Fujita $(2003$, p. 41) relata que esta [...] "é uma das etapas mais importantes do trabalho do bibliotecário indexador, pois tem como objetivo identificar e selecionar os conceitos que representam a essência de um documento".

Dentro desse contexto, acreditamos que as concepções de análise de assunto "orientadas pelo conteúdo e pela demanda", preconizadas por Albrechtsen (1993), são totalmente aplicáveis durante a prática da indexação para catalogação de documentos de áreas científicas especializadas de catálogos coletivos online de bibliotecas universitárias.

O contexto sociocognitivo do usuário, delineado pelo conhecimento prévio que possui sobre a universidade, pesquisas que desenvolve em nível de iniciação científica, grade curricular das disciplinas científicoacadêmicas e pelo catálogo ATHENA, revelou-nos resultados relevantes sobre o uso da LCARB no processo de recuperação da informação.

A LCARB, vista como instrumento mediador entre o usuário e o sistema, obteve um desempenho insatisfatório, demonstrando a incompatibilidade entre a linguagem documentária adotada pelo sistema e a de busca do usuário. 
Os resultados muito abrangentes apresentados pelo sistema foi um dos aspectos mais importantes apontados pelos usuários como fator da realização de buscas por assuntos não condizentes com suas necessidades investigativas, ocasionando uma alta revocação na recuperação da informação. Exemplos:

PVI-U - H1- $4^{\circ}$ Ano [escolha pelo termo genérico; falta de especificidade da linguagem]

[...] $((A S D))$ LEITURA ou só $((A S D))$ ESCRITA...mas você viu os específicos mesmo eu não consigo. Aí essa é a questão ele vem muito...muito geral $[\ldots]$.

PVU-I - B2 - 10 Ano [incompatibilidade entre a linguagem de busca do usuário e a do sistema]

$((\mathrm{S}))[. .$.$] Vou tentar por ((ASD)) DENTES INCISIVOS. Olha,$ tem esse do ((LR)) Celso Eduardo de Moraes Barbosa, de 1973 com o assunto tópico ((ASR)) INCISIVOS (DENTES). 0 jeito que a gente digita é diferente do que tem no computador[...].((ASD)) INCISIVOS CENTRAIS. Nada, de novo. Só tem por ((ASR)) DENTES INCISIVOS. Ninguém vai procurar assim. Ninguém fala dentes incisivos. É incisivo. Os assuntos do computador deveriam ser mais igual ao que a gente procura $[\ldots]$.

Sobre isso, Foskett (1973) relata-nos que a especificidade normalmente é empregada para a indexação de artigos de periódicos disponibilizados em bases de dados de áreas científicas especializadas e por meio de um número maior de termos. Em relação aos livros, estes são, de acordo com o seu conteúdo, catalogados no todo e os assuntos são representados por meio de uma notação de classificação para a organização nas estantes e em um ou dois cabeçalhos de assunto para acesso e busca no catálogo.

Acreditamos, portanto, que um equilíbrio entre a exaustividade e a especificidade no processo de indexação documentária é recomendável, principalmente para o tratamento temático dos livros. Exemplificando tal afirmação, recorremos à área de Odontologia demonstrando que se um livro trata especificamente de Amálgama, Resina composta e Porcelana dentária e o tratamento temático reconhecer o uso da exaustividade, ele vai contemplar também o termo genérico Materiais dentários. Nesse caso, se a necessidade de informação do usuário for referente ao assunto Materiais dentários de uma maneira geral o documento será recuperado. Se ele precisar especificamente de um dos três materiais dentários, o documento também será recuperado.

O desconhecimento sobre a linguagem disponibilizada pelo sistema e sobre o seu emprego para a elaboração de estratégias de buscas, também colaboraram para a formação do elenco de elementos contribuintes para a atuação inadequada da linguagem no processo de 
recuperação. Como solução para esses problemas, os usuários sugerem a utilização de cabeçalhos mais específicos para representarem os conteúdos documentários e a construção de um vocabulário controlado, a partir da linguagem do especialista e do aluno. Exemplo:

PVI-U - H2 - 10 Ano [desconhecimento do usuário sobre a linguagem utilizada pelo sistema]

[...] Vai eu vou procurar agora referente ao ((ASD)) DESENVOLVIMENTO DA CRIANÇA. Não foi encontrado nenhum documento. Vou tentar ((ASD)) DESENVOLVIMENTO INFANTIL $[\ldots]$.

Recorrendo à literatura, verificamos que se o sistema de recuperação da informação disponibilizasse a linguagem documentária na interface de busca, esses transtornos poderiam ser minimizados. As pesquisas de Connaway, Johnson e Searing (1997) e de Oliveira, Alves e Vicente (1997) subsidiam a nossa afirmação, pois o usuário, conhecendo a linguagem do sistema, poderia utilizar os termos adequadamente, agilizando o processo de busca e aumentando sua motivação na execução dessa tarefa. Além disso, estando ela disponível ao usuário, ele poderá realizar a busca por meio da própria linguagem, pois, após a consulta, poderia selecionar os seus termos de interesse e os mesmos seriam automaticamente remetidos para o formulário de pesquisa.

Os usuários também percebem a necessidade da compatibilização entre a LCARB e a linguagem de busca do usuário. Além disso, apresentam sugestões sobre a disponibilização na interface de busca de remissivas Ver e Ver Também, como elos orientadores entre os cabeçalhos procurados por eles e os recuperáveis pela linguagem. Exemplo:

PVG - B2 [incompatibilidade entre a linguagem de busca do usuário e a do sistema; construção de um vocabulário proveniente da linguagem do especialista e do usuário; desempenho insatisfatório na realização de buscas por assunto: resultado abrangente]

\section{Discente}

[...] porque a primeira coisa que eu faço eu entro e coloco o assunto, só que vem uma gama assim enorme assim de coisas e você acaba que tendo assunto ali que não é do seu interesse. Se você coloca uma palavra, e às vezes você põe uma palavra, por exemplo, Inflamação, que é o que a gente estuda bastante, só que você quer em uma determinada área e de repente aparece Inflamação de tudo, de todos os gêneros do corpo humano $[. .$.

\section{Discente}


Mas é que as vezes o vocabulário que ele está utilizando não é o vocabulário nosso de costume

Outrossim, ressaltam também ser de suma importância a disponibilidade de um manual do usuário e a acessibilidade da linguagem para os usuários locais e remotos, como norteadores para a recuperação precisa da informação.

Sobre o catálogo ATHENA, a visão dos usuários mostrou-nos, principalmente, que este deve funcionar à semelhança de uma base de dados, possibilitando a recuperação por assunto de documentos analíticos, como capítulos de livros e artigos de periódicos e a ordenação dos registros recuperados por ordem decrescente de data de publicação, entre outros aspectos.

A respeito disso, o nosso ponto de vista encontra suporte nos fundamentos teóricos de Hjørland $(1997 ; 2002)$, sobre a construção de catálogos coletivos online vistos pela perspectiva de um sistema de informação integrado, objetivando o acesso, a recuperação, a localização e a obtenção rápida e fácil das informações e, também, dos documentos impressos e eletrônicos representativos da necessidade real de informação do usuário e do seu contexto social.

Ressaltamos que os trabalhos desenvolvidos pela IFLA (2003) contribuem com esse cenário, no estabelecimento de diretrizes para a realização da representação bibliográfica focada no usuário e no seu meio, com vistas à indexação para catalogação e o controle do vocabulário, por meio de linguagens documentárias alfabéticas como os principais atores desse processo.

Nessa perspectiva e a partir dos resultados obtidos em nossa pesquisa, julgamos necessária a inferência no contexto da realidade das bibliotecas universitárias da UNESP, propondo recomendações sobre o uso adequado de linguagem documentária no catálogo coletivo online ATHENA, das áreas científicas especializadas para a indexação e recuperação da informação, a partir da construção de um vocabulário controlado específico para a Rede UNESP.

\section{Considerações finais}

A partir dos três aspectos inicialmente abordados em nossa pesquisa e da nossa proposta e objetivo estabelecidos, pudemos verificar que o uso adequado de linguagens documentárias de áreas científicas especializadas ocorre por meio da avaliação quanto à atualização, especificidade e compatibilidade para atender às necessidades de indexação e recuperação da informação. A concepção desse cenário faz-se a partir de uma visão interacionista entre o meio e a percepção dos indivíduos envolvidos nesse processo. 
Sobre a abordagem qualitativa-sociocognitiva com protocolo verbal, adotada como método de avaliação, permitiu-nos observar o uso de linguagens documentárias de catálogos coletivos online de áreas científicas especializadas nos contextos de trabalho dos bibliotecários, verificando o seu "fazer" diário, no uso da linguagem na representação para indexação, a compreensão que possuíam sobre a linguagem documentária adotada pelo sistema, as visões sobre o seu desempenho e o que consideravam como o sistema de organização do conhecimento apropriado para as necessidades de representação e busca por assunto.

O contexto da recuperação da informação com o usuário, possibilitou-nos avaliar o uso da linguagem na elaboração de estratégias de busca, a percepção que possui sobre o seu desempenho na busca por assunto e a compreensão sobre o que considera ser uma atuação satisfatória e uma construção adequada.

Acreditamos, dessa maneira, que é tendência dos catálogos atuarem à semelhança de base de dados e o bibliotecário catalogador atuar, também, como um indexador, reconhecendo a importância desse papel na construção de catálogos coletivos recuperáveis por pontos de acesso de assunto, constituídos a partir da análise e da representação efetiva do assunto do documento, com vistas à recuperação da informação personalizada que retrate as necessidades informacionais do usuário e do seu contexto social.

Dessa forma, a biblioteca universitária, inserida em universo de conhecimento, necessita de produtos e instrumentos que demonstrem essa realidade, pois a linguagem documentária, sendo um componente do catálogo, deve representar esse conteúdo científico de alta especialização, promovendo a mediação e a comunicação entre a indexação e a recuperação da informação para sua comunidade usuária local e remota. Essa linguagem deve ser elaborada a partir de uma concepção multidimensional, contemplando as relações sintático-semânticas entre os termos advindos das áreas científicas especializadas e da linguagem do usuário.

Em associação, os fundamentos teóricos da área de Organização e Representação do Conhecimento para linguagens documentárias, com enfoque nas tecnologias de representação e recuperação da informação, também nos proporcionaram as condições necessárias para a análise dos resultados e discussão sobre a avaliação do uso de linguagem documentária de catálogos coletivos online de áreas científicas especializadas, na perspectiva das bibliotecas universitárias.

\section{Referências}

ALBRECHTSEN, $\mathrm{H}$. Subject analysis and indexing from automated indexing to dominion analysis. The Indexer, London, v. 18, n. 4, p. 219-224, 1993.

ALMEIDA, D. P. R. et al. Paradigmas contemporâneos da Ciência da Informação: a recuperação da informação como ponto focal. Revista 
Eletrônica Informação \& Cognição, Marília, v. 6, n. 1, p. 16-27, 2007. Disponível em: $<$ http://www.portalppgci.marilia.unesp.br/reic/include/getdoc.php?id=209 \&article $=59 \&$ mode $=$ pdf- $>$. Acesso em: 20 out. 2007.

ALMEIDA, M. C. B. Diagnóstico organizacional. In: . Planejamento de bibliotecas e serviços de informação. 2. ed. rev.e ampl. Brasília: Briquet de Lemos, 2005. cap. 4, p. 53-92.

ANSI/NISO Z39.19-2005: guidelines for the construction, format, and management of monolingual controlled vocabularies. Bethesda: NISO, 2005. $184 \quad$ p. Disponível em: $<$ http://www.niso.org/standards/resources/Z39-19-2005.pdf $>$. Acesso em: 30 jan. 2006.

BEGHTOL, C. A proposed ethical warrant for global knowledge representation and organization systems. Journal of Documentation, London, v. 58, n.5, p. 507-532, 2002.

BOCCATO, V. R. C. Avaliação de linguagem documentária em Fonoaudiologia na perspectiva do usuário: estudo de observação da recuperação da informação com protocolo verbal. 2005. 239 f. Dissertação (Mestrado em Ciência da Informação) - Faculdade de Filosofia e Ciências, Universidade Estadual Paulista, Marília, 2005. Disponível em: <http://www.marilia.unesp.br>. Acesso em: 20 maio 2007.

Avaliação do uso de linguagem documentária em catálogos coletivos de bibliotecas universitárias: um estudo sociocognitivo com protocolo verbal. 2009. 301 f. Tese (Doutorado em Ciência da Informação) - Faculdade de Filosofia e Ciências, Universidade Estadual Paulista, Marília, 2009.2 Disponível em: $<$ http://www.athena.biblioteca.unesp.br/exlibris/bd/bma/33004110043P4 2009/boccato vrc dr mar.pdf>. Acesso em: 13 nov. 2009.

CAPURRO, R. Epistemologia e ciência da informação. In: ENCONTRO NACIONAL DE PESQUISA EM CIÊNCIA DA INFORMAÇÃO - ENANCIB, 5., 2003. Belo Horizonte. Anais... Belo Horizonte: UFMG, 2003.

CONNAWAY, L. S.; JOHNSON, D. W.; SEARING, S. E. Online catalog from the users' perspective: the use of focus group interviews. College \& Research Libraries, Chicago, v. 58, n. 5 p. 403-420 Sept. 1997.

CRUESP/BIBLIOTECAS. O Portal dos Sistemas de Bibliotecas das Universidades Estaduais Paulistas. Disponível em: $<$ http://bibliotecascruesp.usp.br/bibliotecas/CRUESP.htm>. Acesso em: 19 jan. 2006.

DAL'EVEDOVE, P. R.; FUJITA, M. S. L. A Cognição profissional de catalogadores de assunto em contexto de biblioteca universitária. In: SEMINÁRIO NACIONAL DE BIBLIOTECAS UNIVERSITÁRIAS - SNBU, 15., 2008, São Paulo. Anais... São Paulo: CRUESP, 2008. p. 1-15. 
DERVIN, B. An overview of sense-making research: concepts, methods and results to date. In: ANNUAL MEETING OF THE INTERNATIONAL COMMUNICATION ASSOCIATION, 1983, Dallas, U.S.A. Disponível em: $<$ http://faculty.washington.edu/wpratt/MEBI598/Methods/An\%200vervie w\%20of\%20Sense-Making\%20Research\%201983a.htm>. Acesso em: 27 maio 2009.

Audience as listener and learner, teacher and confidante: the sense-making approach. In: DERVIN, B.; FOREMAN-WERNET, L. ; . LAUNTERBACH, E. (Ed.). Sense-making methodology reader: selected writings of Brenda Dervin. Cresskill, NJ: Hampton Press, 2003. p. 215231.

FERNÁNDEZ MOLINA, J. C.; MOYA ANEGÓN, F. Los catálogos de acceso público en línea: el futuro de la recuperación de información bibliográfica. [Málaga]: Asociación Andaluza de Bibliotecarios, 1998. 197 p.

FOSKETT, A. C. A abordagem temática da informação. São Paulo: Polígono, 1973. $437 \mathrm{p}$.

FUJITA, M. S. L. A leitura documentária do indexador: aspectos cognitivos e linguísticos influentes na formação do leitor profissional. 2003. 21 f. Tese (Livre-Docência em Análise Documentária e Linguagens Documentárias Alfabéticas) - Faculdade de Filosofia e Ciências, Universidade Estadual Paulista, Marília, 2003.

FUJITA, M. S. L.; NARDI, M. I. A.; FAGUNDES, S. A. A observação da leitura documentária por meio de protocolo verbal. In: RODRIGUES, G. M.; LOPES, I. L. (Org). Organização e representação do conhecimento na perspectiva da ciência da informação. Brasília: Thesaurus, 2003. p. 141178. (Estudos avançados em ciência da informação, v. 2).

GIL URDICIAIN, B. Manual de lenguajes documentales. 2. ed. rev. y ampl. Madrid: Ed. NOESIS, 2004. 280 p.

GONÇALVES, M. C. A indexação em catálogos on-line de bibliotecas universitárias na percepção de usuários integrantes de grupos de pesquisa: uma contribuição ao desenvolvimento de política de indexação na rede de bibliotecas da UNESP. 2008. 140 f. Dissertação (Mestrado em Ciência da Informação) - Faculdade de Filosofia e Ciências, Universidade Estadual Paulista, Marília, 2008.2 Disponível em: <http://www.marilia.unesp.br>. Acesso em: 14 dez. 2008.

HJØRLAND, B. Information seeking and subject representation: an activity-theoretical approach to information science. Westport: Greenwood Press, 1997. 213 p.

Epistemology and the socio-cognitive perspective in information science. Journal of the American Society for Information Science and Technology, New York, v. 53, n. 4, p. 257- 270, 2002. 
INTERNATIONAL FEDERATION OF LIBRARY ASSOCIATIONS (IFLA). Declaração de princípios internacionais de catalogação. Frankfurt: IFLA, 2003. Disponível em: <http://www.dnb.de/standardisierung/pdf/statement portugese.pdf $>$. Acesso em: 03 abr. 2008.

INGWERSEN, P. Search procedures in the library: analysed from the cognitive point of review. Journal of Documentation, London, v. 38, n. 3, p. 165-191, Sept. 1982.

LANCASTER, F. W. Information retrieval systems: characteristics, testing, and evaluation. New York: John Wiley \& Sons, 1968. 222 p.

1987. $114 \mathrm{p}$.

Construção e uso de tesauros: curso condensado. Brasília: IBICT,

NARDI, M. I. A. As expressões metafóricas na compreensão de texto escrito em língua estrangeira. 1993. 260 f. Dissertação (Mestrado em Linguística Aplicada ao Ensino de Línguas) - Pontifícia Universidade Católica, São Paulo.

OLIVEIRA, N. M.; ALVES, M. D. R.; VICENTE, G. O cabeçalho de assunto da Rede BIBLIODATA/CALCO: uso e recuperação na base ACERVUS/UNICAMP. Transinformação, Campinas, v. 9, n. 1, p. 110-123, jan.-abr. 1997.

OLSON, H. A.; BOLL, J. J. Subject analysis in online catalogs. $2^{\text {nd }}$ ed. Englewood: Libraries Unlimited, 2001. 333 p.

OWENS, L. A.; COCHRANE, P. A. Thesaurus evaluation. Cataloging \& Classification Quarterly, New York, v. 37, n. 3/4, p. 87-102, 2004.

PINTO, L. P. A representação documentária e o paradigma social. 2005. 108 f. Dissertação (Mestrado em Ciências da Comunicação) - Escola de Comunicações e Artes, Universidade de São Paulo, São Paulo.

SHANNON, K. L.; GIBBS, M. E. From catalog to OPAC: a look at 25 years to technical services in school libraries. In: SMITH, L. C.; CARTER, R. C. (Ed.). Technical services management, 1965-1990: a quarter century of change and a look into the future. Binghanton: Harworth Press, 1996. Cap. 2, p. 41-53.

TOEWS, L. An evaluation methodology for clinical vocabularies and evaluation for the Read Codes. In: OLSON, H. (Ed.). Connectedness: Information, Systems, People, Organizations. Edmonton: University of Alberta, $1995 . \quad$ Disponível em: <http://www.ualberta.ca/dept/slis/cais/toews.htm>. Acesso em: 03 abr. 2007.

TORRES, L. M. C. Inconsistências de cabeçalhos de assunto: propostas de sistematizacao. 1992. 236 f. Dissertação (Mestrado em Ciência da Informação) - Escola de Comunicação, Instituto Brasileiro de informação 
em Ciência e Tecnologia; Universidade Federal do Rio de Janeiro, Rio de Janeiro.

ZENG, M. L. Knowledge organization systems (KOS). Knowledge Organization: international journal devoted to concept theory, classification, indexing, and knowledge representation, Frankfurt, v. 35, n. 2-3, p. 160-182, 2008.

\section{APÊNDICE 1 - Resultados obtidos a partir das declarações emitidas pelos sujeitos participantes nos protocolos verbais, em grupo e individuais}

\begin{tabular}{|c|c|}
\hline & LINGUAGEM DOCUMENTÁRIA VISTA PELO CONTEÚDO \\
\hline $\begin{array}{c}\text { CATEGORIAS DE } \\
\text { ANÁLISE }\end{array}$ & RESULTADOS \\
\hline $\begin{array}{l}\text { 1. Procedimentos } \\
\text { relacionados à } \\
\text { indexação }\end{array}$ & $\begin{array}{l}\text { - utilização do padrão da UNESP para a indexação na catalogação, sendo que não há } \\
\text { nada específico a respeito (BC-B2); } \\
\text { - análise de assunto entendida como levantamento de assunto (BCI-E2); } \\
\text { - análise de assunto não é realizada adequadamente (BCI-E2; BC-I H1; BCI-H2); } \\
\text { - na prática da catalogação cooperativa, a análise de assunto não é realizada quando } \\
\text { os registros possuem correspondência total ou parcial (IT ou RA); } \\
\text { - falta de sistematização na realização da leitura documentária pelos bibliotecários } \\
\text { das três áreas do conhecimento (BCI-E2; BCI-H2; BCI-B3); } \\
\text { - a ficha catalográfica, as linguagens documentárias e os sistemas de classificação } \\
\text { são fontes de informações para identificar e selecionar os assuntos (Docente H1; } \\
\text { BCI-E2; BC-I H1; BC-I H2); } \\
\text { - LCARB como conhecimento prévio especializado do bibliotecário indexador para a } \\
\text { análise de assunto (BCI-E3; BCI-B3); } \\
\text { - bibliotecários da área de Odontologia recebem treinamento da BIREME para a } \\
\text { análise de assunto (BR-B1); } \\
\text { - procedimentos feitos pelos bibliotecários têm como objetivo atender à demanda } \\
\text { usuária (BCI-H1); } \\
\text { - necessidade de realização da indexação analítica de documentos: capítulos de livros } \\
\text { (BC-B3). }\end{array}$ \\
\hline $\begin{array}{l}\text { 2. Procedimentos } \\
\text { relacionados à } \\
\text { representação } \\
\text { para a indexação }\end{array}$ & $\begin{array}{l}\text { - a realização inadequada da análise de assunto compromete a representação e o uso } \\
\text { da linguagem com cabeçalhos de assunto não correspondentes ao nível em que o } \\
\text { assunto é efetivamente abordado pelo autor (BC-E1;BCI-E1); } \\
\text { - utilização da LCARB para a confirmação e validação dos cabeçalhos (BC-E1; BCI-E1; } \\
\text { BCI-E3); } \\
\text { - utilização de linguagem documentária paralela para os cabeçalhos não disponíveis } \\
\text { na LCARB (BC-B1; BCI-E1; BCI-E2; BCI-H2); } \\
\text { - necessidade de padronização dos assuntos descritos no campo } 690 \text { (BC-E1; BC-E3; } \\
\text { BC-H1); } \\
\text { - representação de conceitos entendida como "encaixar" no cabeçalho (BC-E1); } \\
\text { - opção por representar os conceitos por termos genéricos (BC-E1); } \\
\text { - utilização da LCARB visto como um instrumento "obrigatório" da Rede UNESP para a } \\
\text { representação da informação (BC-B1; BC-B2); } \\
\text { - ausência do uso da lista hierárquica da LCARB (BCI-E1; BCI-E2); } \\
\text { - utilização de cabeçalhos não autorizados pela LCARB, no campo 650, realizada por } \\
\text { algumas bibliotecas participantes da Rede BIBLIODATA (BCI-E2); } \\
\text { - reconhecimento por parte dos bibliotecários da importância do conhecimento sobre } \\
\text { a área científica a ser representada pela linguagem (BC-H3); } \\
\text { - representação feita tem como objetivo atender a demanda usuária (BC-E1; BC-E3; } \\
\text { BC-H1). }\end{array}$ \\
\hline
\end{tabular}




\begin{tabular}{|c|c|}
\hline $\begin{array}{l}\text { 3. Escolha da } \\
\text { linguagem }\end{array}$ & $\begin{array}{l}\text { - LCARB não representa satisfatoriamente os assuntos dos documentos (PVG-E1, } \\
\text { PVG- B1, PVI-C-H2, PVI-C-B2); } \\
\text { - utilização de linguagens documentárias paralelas especializadas, exemplificadas } \\
\text { pelo uso do DeCS (BC-B1); } \\
\text { - necessidade de padronização dos assuntos no campo } 650 \text { (BC-H3); } \\
\text { - necessidade de construção de um vocabulário controlado da Rede UNESP (BC-H3). }\end{array}$ \\
\hline $\begin{array}{l}\text { 4. Escolha do } \\
\text { termo }\end{array}$ & $\begin{array}{l}\text { - a escolha do termo é realizada de acordo com o contexto da biblioteca onde o } \\
\text { usuário está inserido (BC-H1; BCI-E2); } \\
\text { - opção pelo termo genérico nas bibliotecas que possuem cobertura temática nas três } \\
\text { áreas do conhecimento (BC-E1); } \\
\text { - tendência pela opção do termo genérico para a representação do conteúdo } \\
\text { documentário: falta de especificidade da linguagem (BC-B2, PVI-U-H1-40 Ano); } \\
\text { - opção pelo termo específico (BCI-E2). }\end{array}$ \\
\hline $\begin{array}{l}\text { 5. Desempenho } \\
\text { da linguagem no } \\
\text { processo de } \\
\text { representação } \\
\text { para indexação }\end{array}$ & $\begin{array}{l}\text { - desempenho insatisfatório da LCARB ocasionadas pela presença de termos } \\
\text { ambíguos, falta de remissivas, de vocabulário especializado, atualizado, de } \\
\text { especificidade e de normalização dos cabeçalhos, problemas entre cabeçalhos quanto } \\
\text { ao uso de singular e plural, entre outros (BC-H2, BC-H3, BR-B1, Discente E2-1 Ano, } \\
\text { Discente E3-10 Ano); } \\
\text { - tradução dos cabeçalhos de assunto não condizente com o uso que se faz na } \\
\text { terminologia da área científica especializada (PVG - H3); } \\
\text { - utilização de linguagem documentária paralela para os cabeçalhos não disponíveis } \\
\text { na LCARB: Engineering Index, CDU, VocaUSP, DeCS, outras listas de cabeçalhos de } \\
\text { assunto (BCI-E2; PVI-C- B1; PVI-C-B2; PVI-C-B3); } \\
\text { - preocupação sobre como o usuário busca por assunto para a recuperação da } \\
\text { informação (BC-H1); } \\
\text { - disponibilidade da linguagem na interface de entrada de dados (catalogação) do } \\
\text { catálogo ATHENA para a representação da informação a partir da própria linguagem } \\
\text { em conexão com o formato bibliográfico MARC } 21 \text { (BCH1); } \\
\text { - criação de catálogo de termos para representação dos assuntos no campo } 690 \text { (BC- } \\
\text { H3); } \\
\text { - necessidade de construção de um vocabulário controlado para a Rede UNESP (BC- } \\
\text { H3); } \\
\text { - realização da indexação classificatória (BCI-E2). }\end{array}$ \\
\hline
\end{tabular}

Fonte: BOCCATO, 2009, p. 222-224.

\section{APÊNDICE 2 - Resultados obtidos a partir das declarações emitidas pelos sujeitos participantesnos protocolos verbais em grupo e individuais}

\begin{tabular}{|l|l|}
\hline \multicolumn{1}{|l|}{ LINGUAGEM DOCUMENTÁRIA VISTA PELO USO } \\
\hline $\begin{array}{l}\text { CATEGORIAS DE } \\
\text { ANÁLISE }\end{array}$ & \multicolumn{1}{|c|}{ RESULTADOS } \\
\hline $\begin{array}{l}\text { 6. Conhecimento/ } \\
\text { Importância da } \\
\text { linguagem }\end{array}$ & $\begin{array}{l}\text { - necessidade da LCARB ser disponibilizada para consulta e uso pelo usuário na } \\
\text { busca por assunto no sistema (BC-H3); } \\
\text { - desconhecimento por parte do usuário sobre a linguagem documentária utilizada } \\
\text { pelo sistema para a recuperação da informação (Docente B3; Discente E2-10 Ano; } \\
\text { Discente H1-40 Ano; Discente -H2-40 Ano; Discente B3-40 Ano). }\end{array}$ \\
\hline $\begin{array}{l}\text { 7. Estratégia de } \\
\text { busca }\end{array}$ & $\begin{array}{l}\text { - dificuldades manifestadas pelo usuário sobre os procedimentos de elaboração de } \\
\text { estratégias de busca e de uso dos operadores booleanos (Docente B1; Discente H3- }\end{array}$ \\
$\begin{array}{l}\text { 40 Ano; Discente B3-40 Ano); elaboração por parte do usuário das estratégias de } \\
\text { busca da maneira que considera ser a mais correta (Discente H3-40 Ano); } \\
\text { - a busca delegada é considerada por parte do bibliotecário e dos usuários como a } \\
\text { melhor opção para a realização da estratégia de busca (Discente - B2); } \\
\text { - treinamento e prática são ações reconhecidas pelo usuário como importantes para a } \\
\text { elaboração de estratégias de busca (Discente B3-40 Ano); }\end{array}$ \\
\hline
\end{tabular}




\begin{tabular}{|c|c|}
\hline & $\begin{array}{l}\text { - o contexto social como fator de influência sobre a manifestação da necessidade de } \\
\text { informação do usuário (Discente B2). }\end{array}$ \\
\hline $\begin{array}{l}\text { 8. Desempenho } \\
\text { da linguagem no } \\
\text { processo de } \\
\text { recuperação da } \\
\text { informação }\end{array}$ & $\begin{array}{l}\text { - desempenho insatisfatório da LCARB na busca por assunto não correspondendo as } \\
\text { necessidades de recuperação da informação do usuário (Discente-B2-40 Ano); } \\
\text { - falta de especificidade da linguagem ocasionando a alta revocação e a baixa } \\
\text { precisão na recuperação: resultados muito abrangentes (Discente B2; Discente-H1- } \\
10 \text { Ano; Discente } \mathrm{H} 1-40 \text { Ano); } \\
\text { - bibliotecário aponta a opção do usuário na busca pelo título e pelo autor no } \\
\text { catálogo, bem como nas pesquisas por assunto em bases de dados e por palavras } \\
\text { livres em buscadores na Internet (Google) (BCh-E1); } \\
\text { - incompatibilidade entre a linguagem do sistema e a de busca do usuário } \\
\text { presenciada nas três áreas do conhecimento (BC-E1; Docente -B2; Discente B2; } \\
\text { Discente B2-10 Ano); } \\
\text { - sugestão de inserção de remissas Ver e Ver também como atributos da ineficiência } \\
\text { da linguagem na recuperação da informação (BC-H3; PVI-U-H3); } \\
\text { - construção de um vocabulário proveniente da linguagem do especialista e do } \\
\text { usuário (Discente - B2); } \\
\text { - disponibilidade da linguagem na interface de buscas (Discente -B3). }\end{array}$ \\
\hline $\begin{array}{l}\text { 9. Capacidade de } \\
\text { revocação e } \\
\text { precisão do } \\
\text { sistema }\end{array}$ & $\begin{array}{l}\text { - opção pela exaustividade na indexação (BC-E2); } \\
\text { - necessidade da especificidade na indexação (Docente - E2); } \\
\text { - alta revocação na recuperação da busca por assunto (Docente - H2; Discente - B2). }\end{array}$ \\
\hline $\begin{array}{l}\text { 10. Avaliação do } \\
\text { sistema de } \\
\text { recuperação da } \\
\text { informação }\end{array}$ & $\begin{array}{l}\text { - usuários sugerem que o catálogo possibilite a realização de link com buscadores na } \\
\text { Internet como o Google (Docente - E1; Discente B3-10 Ano); } \\
\text { - bibliotecários e usuários consideram, no geral, que a interface do sistema não é } \\
\text { amigável (Docente B3; BC-B3); } \\
\text { - bibliotecário considera o formulário de busca complicado (BC-H3); } \\
\text { - necessidade do sistema oferecer a possibilidade de combinação de campos de } \\
\text { busca (Docente H3); } \\
\text { - a interface de busca por assunto é considerada pelo usuário como satisfatória, } \\
\text { porém poderá ser melhorada, como por exemplo, com a implantação de outros } \\
\text { campos de busca (por tipo de material, indicação da biblioteca depositária, etc. } \\
\text { (Discente E3-10 Ano, Discente B3- } 10 \text { Ano); } \\
\text { - sugestão por parte do usuário sobre a apresentação dos registros serem } \\
\text { recuperados em ordem decrescente de data de publicação (Discente B1-10 Ano); } \\
\text { - necessidade reconhecida por parte dos bibliotecários e usuários sobre o catálogo } \\
\text { possibilitar a recuperação analítica de documentos visando o usuário local e remoto } \\
\text { (BC-H3; Discente H1-10 Ano; Discente B2-10 Ano); } \\
\text { - sugestão por parte dos bibliotecários sobre o sistema possibilitar a opção da busca } \\
\text { por assunto pelo cabeçalho não preferido e que o sistema realize a conversão } \\
\text { automaticamente para o cabeçalho preferido (BC-H2); } \\
\text { - sugestão do bibliotecário sobre o sistema disponibilizar a linguagem documentária } \\
\text { para consulta e uso na busca por assunto, visando o usuário local e o remoto (BCh- } \\
\text { H2); } \\
\text { - folder como fonte de informação sobre o uso do catálogo (BC-B2); } \\
\text { - participação do bibliotecário na construção do sistema (BCh-H2). }\end{array}$ \\
\hline
\end{tabular}

Fonte: BOCCATO, 2009, p. 222-224. 


\section{APÊNDICE 3 - Resultados obtidos a partir das declarações emitidas pelos sujeitos participantes nos protocolos verbais em grupo e individuais}

\begin{tabular}{|c|c|}
\hline \multicolumn{2}{|r|}{ LINGUAGEM DOCUMENTÁRIA VISTA PELA FORMA } \\
\hline $\begin{array}{c}\text { CATEGORIAS DE } \\
\text { ANÁLISE }\end{array}$ & RESULTADOS \\
\hline $\begin{array}{l}11 . \\
\text { Procedimentos de } \\
\text { construção, } \\
\text { atualização e } \\
\text { manutenção da } \\
\text { linguagem }\end{array}$ & $\begin{array}{l}\text { - necessidade de criação de um vocabulário controlado da UNESP (BC-H3; BC-B3); } \\
\text { - construção de um vocabulário proveniente da linguagem do especialista e do } \\
\text { usuário (Discente-B2); } \\
\text { - necessidade de atualização da LCARB (BC-E2, BC-H3; Docente-B1); } \\
\text { - constituição de um grupo de bibliotecários para a construção do vocabulário } \\
\text { controlado da UNESP (BR H3); } \\
\text { - bibliotecários consideram burocráticos os procedimentos da Rede BIBLIODATA para } \\
\text { atualização da LCARB, sendo que alguns não possuem muitos conhecimentos sobre o } \\
\text { "fazer" desse processo (BC-H1; BC-H3). }\end{array}$ \\
\hline $\begin{array}{l}\text { 12. O papel do } \\
\text { bibliotecário na } \\
\text { construção, } \\
\text { atualização e } \\
\text { manutenção da } \\
\text { linquagem }\end{array}$ & $\begin{array}{l}\text { - interação entre os serviços de referência e processamento técnico e estes dois } \\
\text { entre o usuário é reconhecida pelos bibliotecários como importante para a realização } \\
\text { da atualização da LCARB (BC-E1; BC-H1; BC-H2; BC-H3; BC-B1). }\end{array}$ \\
\hline
\end{tabular}

Fonte: BOCCATO, 2009, p. 222-224. 